\title{
2020 ABME Paper Awards
}

\author{
(Published online 20 November 2020)
}

Each year, the top papers in Annals of Biomedical Engineering (ABME) are selected for editorial awards that are presented at the annual Biomedical Engineering Society (BMES) meeting. During the 2020 BMES Virtual Annual Meeting, a total of five awards were presented: two awards for the most citations, ${ }^{3,8}$ one award for the most downloads, ${ }^{9}$ and two editor's choice awards. ${ }^{2,7}$ These papers were selected from a total of 185 papers published in 2019. While the citation and download awards were selected purely quantitatively, the editor's choice awards were selected based on overall impact and quality of the papers. The awards covered a wide range of topics in biomechanics and cardiovascular engineering.

Rotman et al. developed a new polymeric transcatheter aortic valve replacement (TAVR) as a possible alternative to the currently used chemically-fixed xenograft valves. ${ }^{8}$ The hydrodynamic performance of the new valve was compared with a gold standard surgical tissue valve and a clinically used xenograft TAVR valve. The polymeric valve had the best effective orifice area and was the least thrombogenic. The novel valve had a higher regurgitation fraction, but it was still within minimum standard requirements. The newly developed polymeric TAVR valve shows potential for clinical use by outperforming tissue valves.

Hatoum et al.. assessed the effect of transcatheter aortic valve (TAV) misalignment with respect to the aortic root axis on sinus hemodynamics. ${ }^{3}$ Valve misalignment is thought to be one factor associated with increased risk of leaflet thrombosis following TAVR. Sinus hemodynamics were evaluated in vitro with a 3D printed aortic root using particle-image velocimetry. The results of the study showed that valve misalignment does affect sinus hemodynamics by decreasing blood velocity and vorticity, and can potentially increase the risk of leaflet thrombosis.

Stemper et al.. evaluated the role of head impact exposure in concussion tolerance. ${ }^{9}$ Repetitive head impact exposure was quantified in 50 college football players that sustained a concussion during the season. Head impact exposure on the day of injury and the season to date of injury was quantified and compared to a group of matched controls. The results showed an association between repetitive head impact exposure and concussion diagnosis, supporting the need to limit head impacts in athletes to reduce concussion risk.

Rane et al.. used a deep neural network to predict musculoskeletal forces during dynamic movements. ${ }^{7}$ The forces predicted by the network were comparable to values from musculoskeletal modelling when trained on a dataset of kinematic, kinetic, and electromyographic gait measurements. Additionally, when trained on datasets from the international Grand Challenge competitions, the network outperformed most of the winning submissions. A neural network has advantages over a musculoskeletal model for predicting internal forces in computational speed, and could be applicable to real-time gait analysis in a clinical setting.

Courel-Ibáñez et al.. compared the reliability of five different bar velocity monitoring devices by assessing reproducibility and repeatability. ${ }^{2}$ The devices were all used simultaneously while subjects performed two trials each of increasing loads. A linear velocity transducer was the most reliable device, while accelerometer and video-based systems had substantial errors and were not recommended.

These papers follow the five ABME paper awards presented at the 2019 BMES Annual Meeting. ${ }^{1,4-6,10}$ All papers published in ABME during 2020 will be considered for awards to be presented at the 2021 BMES Annual Meeting. Awardees will be notified in July, and invited to receive their awards in person during a plenary session at the meeting. We look forward to recognizing the authors of our most impactful papers at BMES in Orlando next year.

\section{REFERENCES}

\footnotetext{
${ }^{1}$ Ahola, A., R.-P. Pölönen, K. Aalto-Setälä, and J. Hyttinen. Simultaneous measurement of contraction and calcium transients in stem cell derived cardiomyocytes. Ann. Biomed. Eng. 46:148-158, 2018.

${ }^{2}$ Courel-Ibáñez, J., A. Martínez-Cava, R. Morán-Navarro, P. Escribano-Peñas, J. Chavarren-Cabrero, J. J. GonzálezBadillo, and J. G. Pallarés. Reproducibility and repeatability of five different technologies for bar velocity mea-
} 
surement in resistance training. Ann. Biomed. Eng. 47:1523-1538, 2019.

${ }^{3}$ Hatoum, H., J. Dollery, S. M. Lilly, J. A. Crestanello, and L. P. Dasi. Sinus hemodynamics variation with tilted transcatheter aortic valve deployments. Ann. Biomed. Eng. 47:75-84, 2019.

${ }^{4}$ Horvath, M. A., C. E. Varela, E. B. Dolan, W. Whyte, D. S. Monahan, C. J. Payne, I. A. Wamala, N. V. Vasilyev, F. A. Pigula, and D. J. Mooney. Towards alternative approaches for coupling of a soft robotic sleeve to the heart. Ann. Biomed. Eng. 46:1534-1547, 2018.

${ }^{5}$ Lin, Y.-C., J. P. Walter, and M. G. Pandy. Predictive simulations of neuromuscular coordination and jointcontact loading in human gait. Ann. Biomed. Eng. 46:12161227, 2018.

${ }^{6}$ Philips, C., F. Campos, A. Roosens, M. del Carmen Sanchez-Quevedo, H. Declercq, and V. Carriel. Qualitative and quantitative evaluation of a novel detergent-based method for decellularization of peripheral nerves. Ann. Biomed. Eng. 46:1921-1937, 2018.

${ }^{7}$ Rane, L., Z. Ding, A. H. McGregor, and A. M. Bull. Deep learning for musculoskeletal force prediction. Ann. Biomed. Eng. 47:778-789, 2019.

${ }^{8}$ Rotman, O. M., B. Kovarovic, W.-C. Chiu, M. Bianchi, G. Marom, M. J. Slepian, and D. Bluestein. Novel polymeric valve for transcatheter aortic valve replacement applications: in vitro hemodynamic study. Ann. Biomed. Eng. 47:113-125, 2019.
${ }^{9}$ Stemper, B. D., A. S. Shah, J. Harezlak, S. Rowson, J. P. Mihalik, S. M. Duma, L. D. Riggen, A. Brooks, K. L. Cameron, and D. Campbell. Comparison of head impact exposure between concussed football athletes and matched controls: evidence for a possible second mechanism of sport-related concussion. Ann. Biomed. Eng. 47:2057-2072, 2019.

${ }^{10}$ Thesleff, A., R. Brånemark, B. Håkansson, and M. OrtizCatalan. Biomechanical characterisation of bone-anchored implant systems for amputation limb prostheses: a systematic review. Ann. Biomed. Eng. 46:377-391, 2018.

\section{BETHANY ROWSON}

Department of Biomedical Engineering and Mechanics

Virginia Tech

Blacksburg, VA, USA

Electronic mail: browson@vt.edu

Publisher's Note Springer Nature remains neutral with regard to jurisdictional claims in published maps and institutional affiliations. 